\title{
The Reinforcement and Healing of Asphalt Mastic Mixtures by Rejuvenator Encapsulation in Alginate Compartmented Fibres
}

\author{
Amir Tabakovic \\ Technological University Dublin, amir.tabakovic@tudublin.ie \\ W. Post \\ Delft University of Technology \\ D. Cantero \\ Norwegian University of Science and Technology
}

See next page for additional authors

Follow this and additional works at: https://arrow.tudublin.ie/resdirart

Part of the Construction Engineering and Management Commons

\section{Recommended Citation \\ Tabaković, A; Post, W.; Cantero, D.; Copuroglu, O.; Garcia, S.J.; Schlangen, E., 2016 "Reinforcement and healing of asphalt mixtures by rejuvenator encapsulation in alginate compartmented fibres". IOP Smart Materials and Structures, Special Edition on Self Healing Materials. Vol. 25, 8. doi:10.1088/0964-1726/25/ $8 / 084003$}

This Article is brought to you for free and open access by the Directorate of Research and Enterprise at ARROW@TU Dublin. It has been accepted for inclusion in Articles by an authorized administrator of ARROW@TU Dublin. For more information, please contact arrow.admin@tudublin.ie, aisling.coyne@tudublin.ie, gerard.connolly@tudublin.ie.

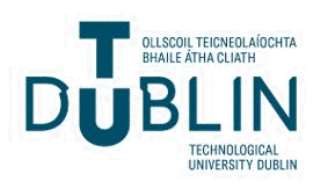




\section{Authors}

Amir Tabakovic, W. Post, D. Cantero, Oguzhan Copuroglu, S. J. Garcia, and E. Schlangen 


\title{
The Reinforcement and healing of asphalt mastic mixtures by rejuvenator encapsulation in alginate compartmented fibres
}

Tabaković, A. ${ }^{1 *}$; Post, W. ${ }^{2}$; Cantero, D. ${ }^{3}$; Copuroglu, O. ${ }^{1}$; Garcia, S.J. ${ }^{2}$; Schlangen, E. ${ }^{1}$

${ }^{1 .}$ Materials \& Environment, Faculty CiTG, Delft University of Technology, The Netherlands.

2. Novel Aerospace Materials group, Faculty of Aerospace Engineering, Delft University of Technology, The Netherlands.

3. Norwegian University of Science and Technology, Trondheim, Norway.

\begin{abstract}
This paper explores the potential use of compartmented alginate fibres as a new method of incorporating rejuvenators into asphalt pavement mixtures. The compartmented fibres are employed to locally distribute the rejuvenator and to overcome the problems associated with spherical capsules and hollow fibres. The work presents proof of concept of the encapsulation process which involved embedding the fibres into the asphalt mastic mixture and the survival rate of fibres in the asphalt mixture. To prove the effectiveness of the alginate as a rejuvenator encapsulating material and to demonstrate its ability survive asphalt production process, the fibres containing the rejuvenator were prepared and subjected to Thermogravimetric Analysis (TGA) and Uniaxial Tensile Test (UTT). The test results demonstrated that fibres have suitable thermal and mechanical strength to survive the asphalt mixing and compaction process. The CT scan of an asphalt mortar mix containing fibres demonstrated that fibres are present in the mix in their full length, undamaged, providing confirmation that the fibres survived the asphalt production process. In order to investigate the fibres physiological properties and ability to release the rejuvenator into cracks in the asphalt mastic, the Environmental Scanning Electron Microscope (ESEM) and optical microscope analysis were employed. To prove its success as an asphalt healing system, compartmented alginate fibres containing rejuvenator were embedded in asphalt mastic mix. The samples where then subjected to multiple local damaging and healing events and the degree of healing was quantified. The research findings indicate that alginate fibres present a promising new approach for the development of self-healing asphalt pavement systems.
\end{abstract}

Key Words: Self-healing, Asphalt pavements, Compartmented fibres, Sodium Alginate, Rejuvenation.

\section{Introduction}

Asphalt pavement is a self-healing material [1]. When subjected to rest periods, asphalt pavement has the potential to restore its stiffness and strength by closing the micro cracks which occur in the material over time. Cracks form in the asphalt pavement as a result of traffic loads

\footnotetext{
*Corresponding author: a.tabakovic@tudelft.nl
} 
and severe environmental conditions. Long exposure to these conditions causes the asphalt pavement to age and this, in turn, reduces its ability to self-repair. However, it is possible for a pavement to recover its self-repair mechanism via the addition of bitumen with a higher penetration value or via the addition of a rejuvenating agent [2-5].

A rejuvenator is an engineered cationic emulsion containing maltenes and saturates. The primary purpose of rejuvenator is to diffuse into the aged binder and restore its original molecular structure in order to extend the pavement life. Pavement lifespan is extended by adjusting the properties of the asphalt mix, i.e. reducing its stiffness [3]. Some commercially available rejuvenating agents include: Modeseal R20, Reclamite, Paxole 1009, Cyclepave and ACF Iterlene 1000. A recent study by Garcia et. al. [6] and Su et al. [7] demonstrated that a by-product of vegetable and waste cooking oil can also be used as a rejuvenator. When the cracks within the surface layer of the asphalt pavement are still in an early phase, it is possible to apply a rejuvenator thereby preventing further crack propagation and pavement failure [8]. By applying the rejuvenator to the surface course, the life span of the asphalt pavement can be extended by several years, although, this only applies to the top centimetres of the asphalt pavement. Shen et al. [9] found that no rejuvenators could penetrate further than $20 \mathrm{~mm}$ into asphalt pavement layer, indicating that any damage (cracks) occurring at bottom of the asphalt layer will not be repaired. A further issue encountered when applying the rejuvenator to the asphalt pavement is the necessity for road closures. The rejuvenators may also cause a significant reduction in the surface friction of the pavement and may be harmful to the environment. The inclusion of a rejuvenator into the asphalt mix via microcapsules offers the potential to overcome these problems [7, 10-12]. The underlying principle is that when micro cracks begin to form within the pavement system, they will encounter a capsule. The fracture energy at the tip of the crack will open the capsule, thereby releasing the rejuvenator. The rejuvenator diffuses into the asphalt binder, softens the binder allowing it to flow and seal up the crack, thus preventing its further propagation. The process prevents the formation of micro cracks within the pavement mix and thus will prevent the complete failure of the pavement system. Su and Schlangen [11] and García et al. [12] demonstrated that various types of capsules containing rejuvenator can be produced and that these capsules are sufficiently thermally and mechanically stable to survive the asphalt production process. However, a difficulty with this approach is that large amounts of microcapsules are needed to make the process effective. The addition of large quantities of microcapsules into the asphalt mix can 
et al. [6] and Sun et al. [13] reported that asphalt stiffness was reduced when microcapsules

2 were added. They explained that softening of asphalt binder (viscosity reduction) was caused

3 by the rejuvenator release. However, it is well documented [14] that deformation in the asphalt

4 mix is caused by sand granulates. It is possible that due to the inclusion of microcapsules, sand

5 like particles caused increased asphalt mix deformation, i.e. rutting. Furthermore, the chemical

6 compounds used in the production of microcapsules, such as melamine-formaldehyde [15], in

7 large quantities could pose an environmental threat via leaching. The encapsulation of

8 rejuvenator in alginate-based compartmented fibres is explored here as a solution to these

9 problems in asphalt mixtures. Alginates are linear water soluble polysaccharides comprising of

10 (1 - 4) linked units of $\alpha-\mathrm{D}$ - mannuronate $(\mathrm{G})$ and $\beta-\mathrm{L}$ - guluronate $(\mathrm{M})$ at different proportions

11 and different distributions within the chains [16]. Their functional properties are strongly

12 related to composition (G/M ratio) and sequence of the uronic acids. The chemical formula for

13 sodium alginate is: $\mathrm{C}_{6} \mathrm{H}_{7} \mathrm{O}_{6} \mathrm{Na}$ and its structural formula is shown in Figure 1.

14

15

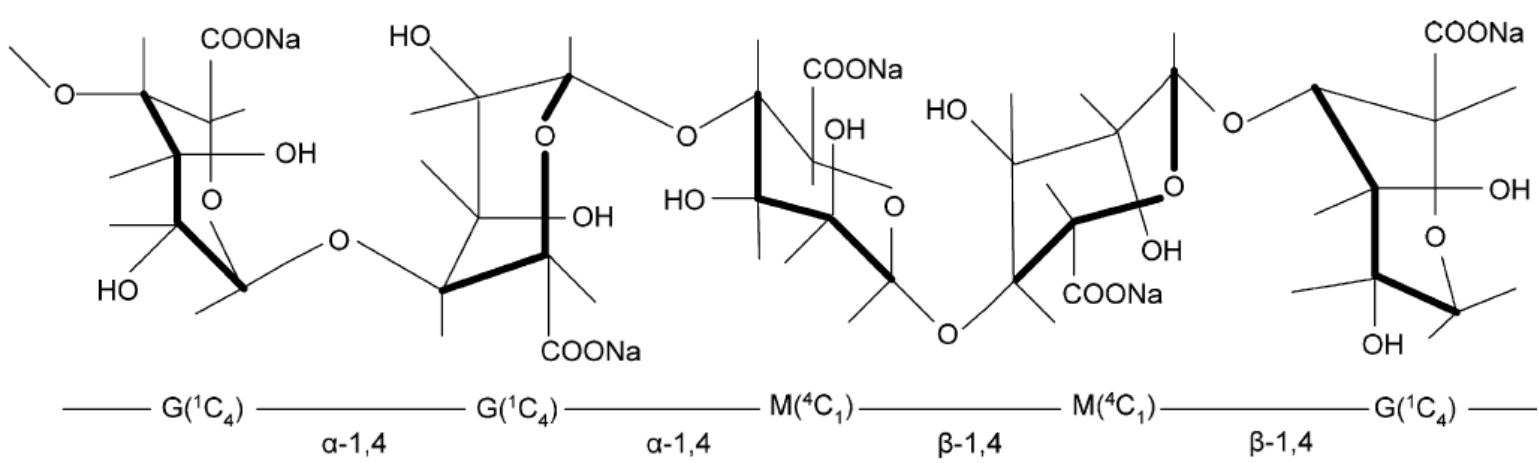

Figure 1 Structural formula of Sodium Alginate.

Alginates are present in brown algae and can also be found in metabolic products of bacteria, e.g. pseudomonas and azotobacter [17-19]. Alginates are commonly used as food additives, gelling agents, wound dressings and for drug delivery [20-22]. Currently the alginate has been investigated for use in the field of material self-healing technology. It has been used for the encapsulation of: i) bacteria in microcapsules for concrete healing [23] and ii) healing agent (solvents) for thermoplastic composite material healing [24-26]. The main advantages of the sodium alginate as encapsulating material are that it is:

i) low cost,

ii) organic, low environmental impact,

iii) self-degrading. 
1 This paper investigates the applicability of the compartmented alginate fibre containing 2 rejuvenator as a healing agent delivery and healing triggering mechanism for asphalt pavements. To prove the concept, compartmented alginate fibres containing rejuvenator were prepared and embedded in an asphalt mastic mix. The samples where then subjected to multiple local damaging and healing events and the degree of healing that resulted was quantified. This research demonstrates the first promising results using alginate to promote asphalt healing and paves the way for future research in this area.

\section{Experimental}

\subsection{Numerical study of fibres vs microcapsules}

In order to verify the benefits of the fibres over microcapsules and to optimise the amount of fibres in the mix, a numerical modelling approach was used. The model was created using Matlab software. The model simulates packing of the microcapsules and fibres in a given volume of asphalt pavement. The Monte Carlo simulation technique was used to analyse the probability distribution of volume released at a crack plane from spherical capsules and from capsule agglomerates emulating compartmented fibre architectures.

\subsection{Materials and production processes}

\subsubsection{Compartmented Alginate Fibres Production}

The compartmented fibres were spun from an emulsion of rejuvenator suspended in a water solution of sodium alginate. To this aim a $6 \mathrm{wt} . \%$ solution of sodium alginate in de-ionized water was prepared. At the same time a $2.5 \mathrm{wt} \%$ poly (ethylene-alt-maleic-anhydride) (PEMA) polymeric surfactant solution was prepared by dissolving the copolymer in water at $70^{\circ} \mathrm{C}$ and mixing it for 60min. After the PEMA has been dissolved in the water it was allowed to cool to room temperature $\left(20 \pm 2^{\circ} \mathrm{C}\right)$ and was added to the rejuvenator in proportion of: $40 \%$ PEMA and $60 \%$ rejuvenator, forming a healing agent solution. Sodium alginate and PEMA/rejuvenator solutions were then combined in rejuvenator/alginate 1/1.3 proportion. The solution was mixed at 40rpm for 20 seconds. It is important to note that the stirring rate and stirring time can be used to control the size of the rejuvenator droplets in the solution and thus the size of the rejuvenator compartments $[11,25]$. If the stirring rate is low and stirring time is short, the droplets will be larger, but if the stirring rate is high and the stirring time is long, the droplets will be smaller. 
1 The emulsion was then spun with a plunger-based lab scale wet spinning line in a conventional

2 wet spinning process $[25,26]$ to form the rejuvenator-filled compartmented fibres. A spinneret

3 containing one capillary of $0.5 \mathrm{~mm}$ diameter and $1.5 \mathrm{~mm}$ length was used. The extrusion rate

4 was $1.93 \mathrm{~cm}^{3} / \mathrm{min}$ and the take up speed was $19.1 \mathrm{~m} / \mathrm{min}$. The coagulation bath was $0.8 \mathrm{~m}$ long

5 and contained a $0.45 \mathrm{M}$ solution of $\mathrm{CaCl}_{2} \cdot 6 \mathrm{H}_{2} \mathrm{O}$. More details on the fibre preparation and

6 spinning process can be found elsewhere [26]. All chemicals used in the process were purchased

7 from Sigma Aldrich, The Netherlands. Figure 2 shows an image of a compartmented alginate

8 fibre encapsulating rejuvenator captured by optical microscope technique.

10

11

12

13

14

15

16

17

19

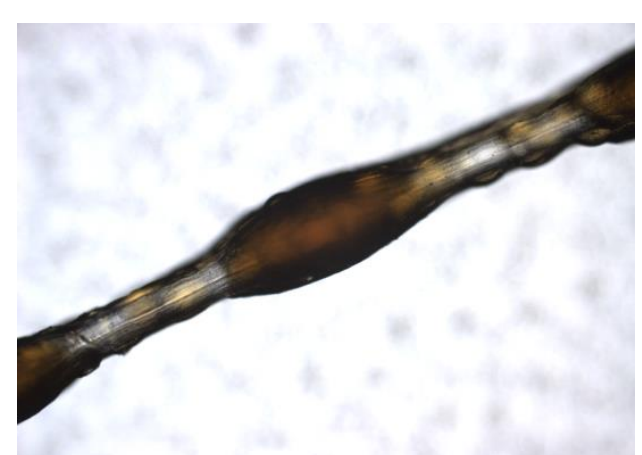

Figure 2 An image of a compartmented alginate fibre encapsulating rejuvenator captured by optical microscope. Plane polarised light imaging. Field of view is approximately $3 \mathrm{~mm}$.

\subsubsection{Asphalt mastic mix design and mixing procedure}

In an effort to evaluate the efficiency of rejuvenator encapsulated in compartmented alginate fibres, a porous asphalt mastic mix was designed. The objective was to reproduce mastic mix proportions as they exist in a typical open graded asphalt wearing courses used in the Netherlands [4, 27]. The composition of porous mix design is given in Table 1.

Table 1Constituent proportion design for Porous Asphalt Mix

\begin{tabular}{|l|l|}
\hline \multirow{2}{*}{ Mix Constituent } & \multicolumn{1}{|c|}{$\begin{array}{c}\text { content in } \\
\text { mix }\end{array}$} \\
\cline { 2 - 2 } & without fibres \\
\hline C $22.4-16$ & 2.5 \\
\hline C16.0 - 11.2 & 20 \\
\hline C $11.2-8.0$ & 35 \\
\hline C $8.0-5.6$ & 20 \\
\hline C5.6-2.0 & 7.5 \\
\hline Sand & 10.5 \\
\hline Filler & 4.5 \\
\hline
\end{tabular}


1 Using the porous asphalt mix designs, as shown in Table 1, the mastic mixtures constituent

2 proportions were calculated using the following approach:

$$
C_{M}=\frac{100 \times C_{P A}}{\sum C_{P A}}
$$

4 where:

$C_{M} \quad=$ percentage of a constituent in the mastic mix (e.g. sand),

$C_{P A}=$ percentage of a mastic mix constituent in the porous asphalt mix (e.g. sand),

$\sum C_{P A}=$ sum of percentages of all mastic mix constituents in the porous asphalt mix (e.g. sand and filler).

The mastic mix proportions were calculated using only constitutive materials passing through a $2 \mathrm{~mm}$ sieve size, namely sand and filler. The sandstone used (greywacke) was sources from the Bremanger quarry in Norway, the filler material used was hydrated lime (Wigro 60K) and for the bitumen, pen 70/100 was used in this research. Table 2 summarises these mix constituents and shows their proportions in the mix with and without fibres. The length of the fibres included in the mix was $10 \mathrm{~mm}$.

Table 2 Mastic mix design. Percentage content of constituents is given by weight.

\begin{tabular}{|l|l|l|}
\hline \multirow{2}{*}{ Mix Constituent } & \multicolumn{2}{|c|}{ \% content in mix } \\
\cline { 2 - 3 } & without fibres & with fibres \\
\hline Sand & 50 & 49.4 \\
\hline Filler & 25 & 24.7 \\
\hline Bitumen & 25 & 24.7 \\
\hline Fibre & 0 & 1.3 \\
\hline
\end{tabular}

During the mastic mix design stage, it was important to consider the binder film thickness on the aggregate. Having removed the large aggregates $(>2 \mathrm{~mm}$ ) from the mix, it was necessary to establish the binder film thickness for the remaining fine aggregates $(\leq 2 \mathrm{~mm})$ in order to calculate the required added binder content for the mix. The binder film thickness should remain consistent between the original porous mix and the mastic mix. In order to ensure this, the standard calculation of bitumen film thickness as presented within the Shell Bitumen Handbook [28] was employed.

$$
T=\frac{b}{100-b} \times \frac{1}{D_{b}} \times \frac{1}{S A F}
$$

where: 
$T=$ bitumen film thickness (m),

$D_{b} \quad=$ density of bitumen $\left(\mathrm{kg} / \mathrm{m}^{3}\right)$,

$S A F=$ surface area factor $\left(\mathrm{m}^{2} / \mathrm{kg}\right)$,

$b \quad=$ bitumen content $(\%)$.

The data presented in Table 2 illustrates an increase in added binder content in the mastic mix in comparison to the $4.5 \%$ typically used in the binder course mix. This occurs as a result of the increase in the surface area of the aggregates in the mastic mix. The mastic mix contains only fine aggregate, which has a greater surface area than a mix containing large aggregates. The surface area of the porous asphalt mix was $2.4 \mathrm{~m}^{2} / \mathrm{kg}$, whereas for mastic it was $16.9 \mathrm{~m}^{2} / \mathrm{kg}$. In order to ensure the retention of the same aggregate binder film thickness, a greater percentage of binder was added to the mastic mix. By gauging the exact volumetric composition of the original mix the target density of the mastic mix was $2.0 \mathrm{~g} / \mathrm{cm}^{3}$.

The asphalt mastic mix was prepared using a 51 Hobart mixer. Prior to mixing, all mix constituents were preheated to $160^{\circ} \mathrm{C}$ for 2 hours. During the mixing process sand, filler and bitumen were mixed first, fibres were gradually added to the mix in order to avoid conglomeration of fibres within the mix. The fibres were gradually inserted into the mastic mix which resulted prolonged asphalt mixing period causing the mix to cool down and reduce its workability. Therefore, the mix had to be reheated several times at $160^{\circ} \mathrm{C}$. The Final mixing was performed by hand, in order to ensure that the mix constituents (sand, filler and fibres) were fully and evenly coated by the bitumen.

\subsection{Fibre and composite characterization}

\subsubsection{Environmental Scanning Electron Microscope (ESEM)}

The Environmental Scanning Electron Microscope (ESEM) was used to evaluate the morphology of the rejuvenator compartments within the sodium alginate fibres. For this purpose, a Philips XL30 ESEM system was employed. Low accelerating voltage of 10kV and a beam current of less than $1 \mathrm{nA}$ were used to limit the electron beam damage on the heat sensitive polymeric fibres.

\subsubsection{Thermogravimetric analysis (TGA)}

The thermal stability characterization of Sodium Alginate fibres containing rejuvenator was performed using NETZSCH STA 449 F3 Jupiter TGA system, at a scanning rate of $6.5^{\circ} \mathrm{C} / \mathrm{min}$ in Argon gas (Ar) at flow of $50 \mathrm{ml} / \mathrm{min}$. 


\subsubsection{Uniaxial Tensile Test (UTT)}

2 The rejuvenator-containing alginate fibres were tested in tension using a micro tensile testing 3 machine with $50 \mathrm{~N}$ load cell and at a cross-head speed of $0.01 \mathrm{~mm} / \mathrm{s}$. Fibres (cut from a continuous filament of approximately $10 \mathrm{~m}$ long) were glued onto supporting brass plates with a gauge length of $4 \mathrm{~mm}$ accordingly. A batch of 20 fibres were tested successfully. The fibre strain was measured from the machine cross-head displacement taking into account the system compliance.

\subsubsection{Micro-CT Scan}

The X-ray micro-tomography was used to observe whether the fibres survived the asphalt mixing and compaction procedure. For this purpose a Phoenix Nanotom CT scanner with a resolution of $\left(4 \mu \mathrm{m}^{3}\right)$ per voxel was employed.

A bitumen test sample of dimension $20 \mathrm{~mm}$ diameter and $23 \mathrm{~mm}$ height was produced containing the $20 \%$ fibres by weight. However, a difficulty was that fibres are of similar density as asphalt binder and could not detected by the X-ray tomography. In order to visualise the fibres in the asphalt mastic mix, the alginate fibres were gold coated using the plasma sputtering technique, a Balzer Union sputter coater model SCD 040was used.

The samples were rotated along their longitudinal axis and three X-ray attenuation images were recorded and averaged every $0.25^{\circ}$. The image reconstruction was done using the GE software and slide volume was calculated using the Volume Studio Max software from Volume Graphics. The ImageJ 3D Viewer software was employed in order to reconstruct the 3D image of the fibres in the mastic mix. The X-ray tomography in combination with computer graphics allowed visualizing the fibres survival of the asphalt mixing and compaction processes and distribution of the fibres throughout the asphalt mastic specimen.

\subsubsection{Optical microscopy}

A Leica 2500P polarised light microscope was used to observe the rejuvenator release from the fibre compartments and its capillary flow. A microscopic image of the samples were acquired with a Leica DFC310FX digital camera at $1392 \times 1040$ uninterpolated resolution for image analysis and publication.

Several attempts were made to record the rejuvenator release from the capsule into the crack 
1 alginate fibre and same colouring it was not possible to capture the rejuvenator release using any of the above mentioned techniques (ESEM, CT Scan or Optical microscopy). Therefore, a sample was prepared by placing an alginate fibre containing rejuvenator capsules onto the object glass. The cyanide acrylate was used as glue, which was applied on top of the fibre imitating a transparent bitumen matrix. An artificial incision was made in the glue matrix and fibre using a surgical scalpel. The software Leica LAS Live Image Builder was used to record the rejuvenator release and its capillary flow.

\subsection{Fibre ageing and healing evaluation of asphalt mastic mixtures}

\subsubsection{Three-Point Bend (3PB) test}

The Three-Point Bending (3PB) test method, as described in ASTM E 1820 [29], was employed to determine the healing efficiency of the rejuvenator encapsulated in the compartmented sodium alginate fibres. Test specimens (length $=120 \mathrm{~mm}$, width $=25 \mathrm{~mm}$ and thickness $=$ $20 \mathrm{~mm}$ ) were cast in specially designed silicon moulds. The notch was not machined in the test specimen in order to allow formation of micro crack at underside of the test specimen and to initiate multi crack healing events. Schematic representations of the test system and test sample are presented in

a)

Figure 3.

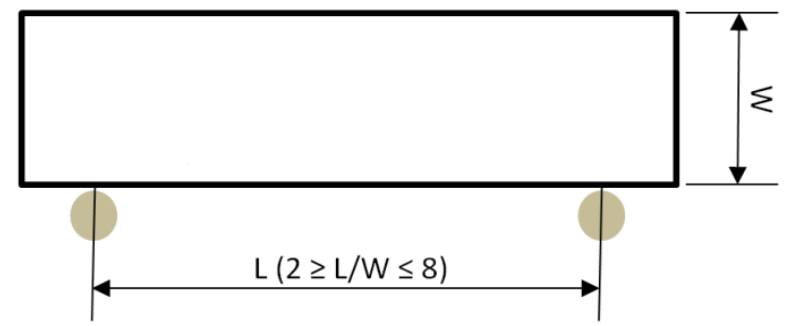

Where: $L=100 \mathrm{~mm}, W=25 \mathrm{~mm}$ and $b=20 \mathrm{~mm}$

a)
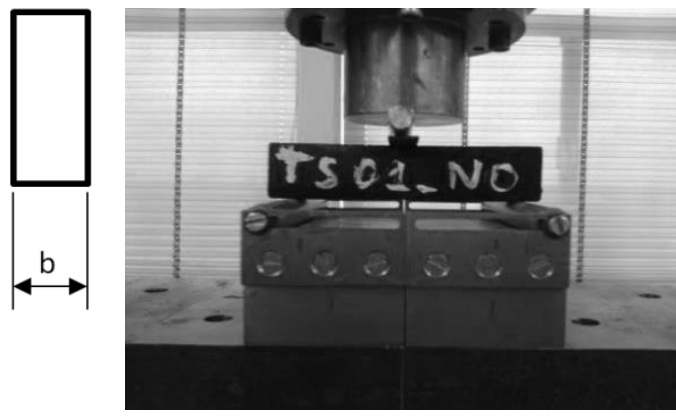

b)

Figure 3 a) Schematic representation of a 3PB test specimen, b) view of the 3PB loading fixture.

The 3PB test configuration was selected because it allows testing of both fibre functionality (compartment opening, release of the healing agent into the cracked matrix) and the effectiveness of the healing agent (rejuvenation, adhesion restoration of the separated surfaces). This test configuration offers several advantages with respect to other testing set-ups in order to test multiple release and healing with the same fibre $[25,30]$. The 3PB test geometry allows localization of the damage (development of micro cracks) along the underside specimen face. 
1 It allows for the initiation and growth of micro cracks along the surface, demonstrating that the

2 healing system is capable of multi crack healing and also testing the fibre healing function for 3 subsequent (multiple) healing events. The test also allows for large cracks to form rapidly which

4 causes full test specimen failure, this can be achieved by increasing the loading rate or reducing 5 the test temperature [30].

6

The three-point bending tests were conducted on an Instron $887210 \mathrm{kN}$ uniaxial testing frame. The tests were conducted at test rate of $0.1 \mathrm{~mm} / \mathrm{s}$. The displacement was measured from the machine cross-head displacement taking into account the system compliance.

The testing programme comprised of two test regimes:

i. Ageing effect on fibre within asphalt mastic,

ii. Healing efficiency of the asphalt mastic containing fibres.

\subsubsection{Ageing effect on fibre within asphalt mastic}

In order to investigate short and long term ageing effects on the compartmented fibres containing rejuvenator, the asphalt mastic mix containing alginate fibres, as shown in Table 2, was prepared and beam test specimens shown

Figure 3 were produced. The ageing programme consisted of three protocols:
i. No ageing,

ii. Short ageing, 4 hours at $135^{\circ} \mathrm{C}$ in forced air draft oven - representing 2 years field ageing.

iii. Long term ageing, 4 hours at $135^{\circ} \mathrm{C}$ followed by 4 days at $85^{\circ} \mathrm{C}$ in forced air draft oven - representing 15 years field ageing.

The ageing protocol was adopted from Kliewer et. al. [31]. Recently Casado Barrasa et. al. [32] successfully used a similar protocol to investigate the effect of short and long term ageing of the asphalt mix containing microcapsules encapsulating asphalt binder rejuvenator.

\subsubsection{Healing efficiency of the asphalt mix containing fibres}

The testing programme consisted of two protocols:

Test 1. bending at $20^{\circ} \mathrm{C}$ to allow micro crack formation followed by healing at $20^{\circ} \mathrm{C}$ during different times. 
Test 2. bending at $-5^{\circ} \mathrm{C}$ to allow large crack formation, i.e. full failure, followed by healing at $20^{\circ} \mathrm{C}$ healing at different times. Up to three bending-healing cycles were applied using both protocols.

Table 3 summarises the healing programme for both tests. The increased healing period for each consequent step was used because it was expected that after each bending test, the damaged area in the test specimen would increase and require a longer healing period. A similar bitumen healing programme was reported by Qiu et al. [33]. The reasoning behind the increase of the healing time for the test 2 , in comparison to test 1 healing programme, was the large damage (crack) area of the test specimen. It was thought that with increased healing time, the material recovery will improve.

Table 3 Healing programme for Test 1 and 2.

\begin{tabular}{|c|c|c|}
\hline Healing stage & $\begin{array}{l}\text { Test } 1-\text { bending temperature } \\
20^{\circ} \mathrm{C}\end{array}$ & $\begin{array}{l}\text { Test } 2 \text { - bending temperature - } \\
5^{\circ} \mathrm{C}\end{array}$ \\
\hline 1 & 30 mins after first bending & $3 \mathrm{~h}$ after first bending \\
\hline 2 & $1 \mathrm{~h}$ after second bending & $12 \mathrm{~h}$ after second bending \\
\hline 3 & $3 \mathrm{~h}$ after third bending & - \\
\hline
\end{tabular}

\section{Results and Discussion}

\subsection{Numerical model fibres vs microcapsules}

Figure 4 a) and b) illustrates the two models, where capsules and fibres constitute $5 \%$ of the model volume $\left(1 \mathrm{~mm}^{3}\right)$. Figure $4 \mathrm{c}$ ) shows the compartmented fibre model packed in a model of $1 \mathrm{~mm}^{3}$ volume, constituting $5 \%$ of the model volume (this volume is equivalent of $5 \%$ microcapsules/fibres in asphalt mix by weight as presented in Table 2). The model allows control of the capsule radius, where $r=50 \mu \mathrm{m}$ with a standard deviation of 25 and max radius $=100 \mu \mathrm{m}$ and min radius $=25 \mu \mathrm{m}$. The fibre radius is also $\mathrm{r}=50 \mu \mathrm{m}$, where its radius/length ratio was $1 / 4$. Due to the small size of the capsule and fibre radius model, the volume of model had to be small, in this case $1 \mathrm{~mm}^{3}$. When a planar crack is introduced along the length of the model, all of the capsules and fibres intersected by the crack are considered to be fractured. Full capsule or fibre volume is used in calculation of rejuvenator volume released in the crack, i.e. thickness of the capsule or fibre walls is not taken in account. 


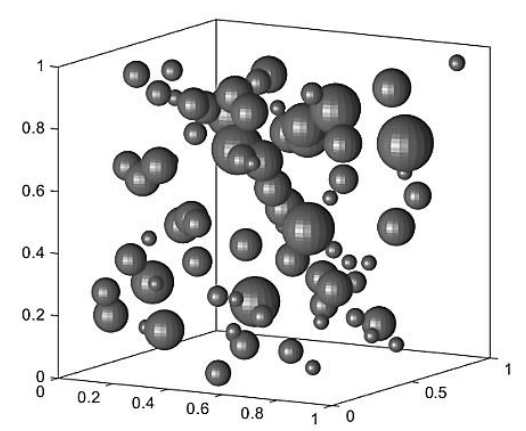

a)

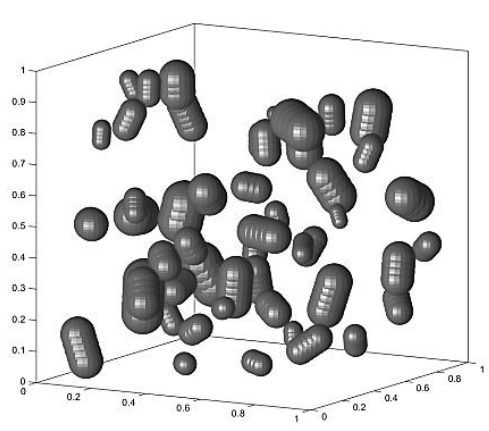

b)

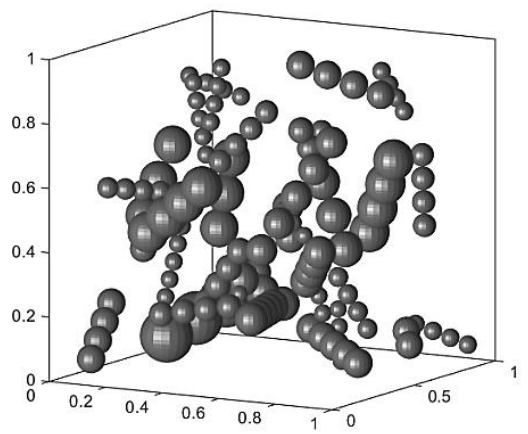

c)

Figure 4 Random samples packing models a) microcapsules, b) hollow fibres and c) compartmented fibres packing in the asphalt mix, volume $1 \mathrm{~mm}^{3}$.

The Monte Carlo simulation technique was used to analyse the probability distribution of volume of rejuvenator released at a crack plane from spherical capsules and from capsule agglomerates. Each model is randomly sampled 1000 times and an average result was taken as an indicator of the volume of rejuvenator released. The results in Figure 5 show that the amount of rejuvenator released via hollow fibres is double than that released by the microcapsules. However, a potential difficulty with the use of hollow fibres within an asphalt pavement is that if the volume of rejuvenator released is greater than volume of the crack it can cause oversoftening of the binder and thus reduce material stiffness in the asphalt pavement, this may induce rutting in the pavement. Another disadvantage of hollow fibres as a rejuvenator delivery system is that they only work for one healing event (one crack healing). Any additional cracks occurring in the pavement will propagate though the pavement layer and potentially cause pavement failure. The use of compartmented fibres provides a potential solution to these issues. Compartmented fibres store the healing agent in the pockets throughout the length of the fibre. For this study, it was decided to create compartment fibres by joining microcapsules into a single fibre. Each capsule in a specific fibre is of a same size, though the fibre size and length in the model can vary. Figure 4c) shows the numerical model compartmented fibres packed in a model of $1 \mathrm{~mm}^{3}$ volume. The results show that using compartmented fibres allows a reduced volume of rejuvenator to be released into the crack, see Figure 5. The results also demonstrate that volume of the capsules within the mix has a minimal effect on rejuvenator release, indicating that capsule size controls the amount of rejuvenator released. These results confirm that the best solution for encapsulation of the rejuvenator in the self-healing asphalt pavement system is the compartmented fibre method. 


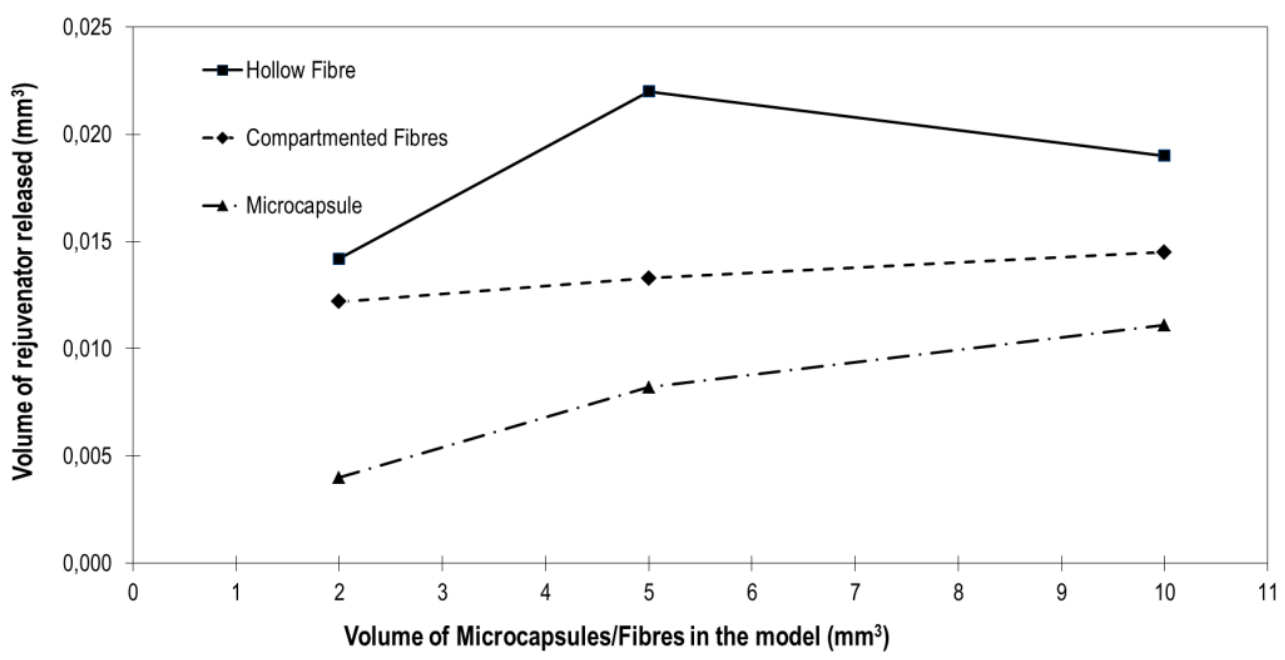

2 Figure 5 Amount of rejuvenator released using various encapsulation method.

\section{$3 \quad 3.2$ Rejuvenator encapsulation and fibre behaviour}

4 Figure 6 shows several ESEM images of compartmented fibres. As can be seen in Figure 6, the 5 rejuvenator was distributed along the fibre axis. The cross-sectional image illustrates that the compartments are contained within the core of the fibre, and have not induced significant 7 change in the local filament diameter. Under non-optimized processing conditions, fibres with 8 an average $170 \mu \mathrm{m}$ diameter, an average compartment diameter of $65 \mu \mathrm{m}$ and an aspect ratio 9 (length to diameter) of 4.0, were obtained.

10
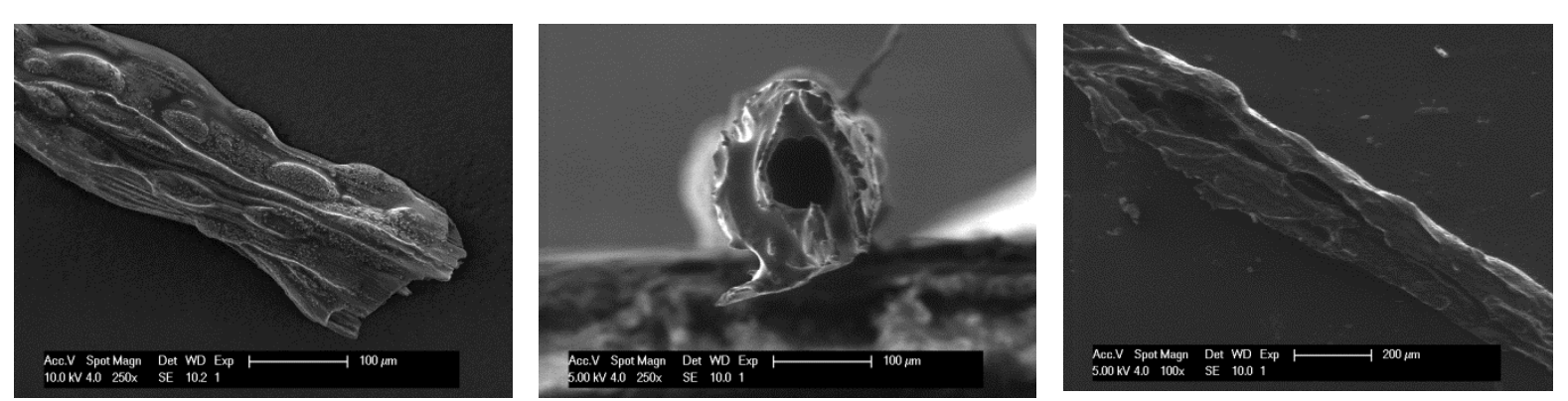

11 Figure 6 ESEM micrographs of a fibre a) general view, b) dimeter cross-section and c) a longitudinal crosssection - revealing one large and two small elliptical compartments.

13

14 Figure 7 shows a) fibre compartment filled with the rejuvenator and b) the release of the 15 rejuvenator from the alginate fibre compartment and rejuvenator capillary flow into the crack.

16 These images demonstrate that compartment fibres can deliver rejuvenator for local damage 17 repair within asphalt mastic mixtures. 


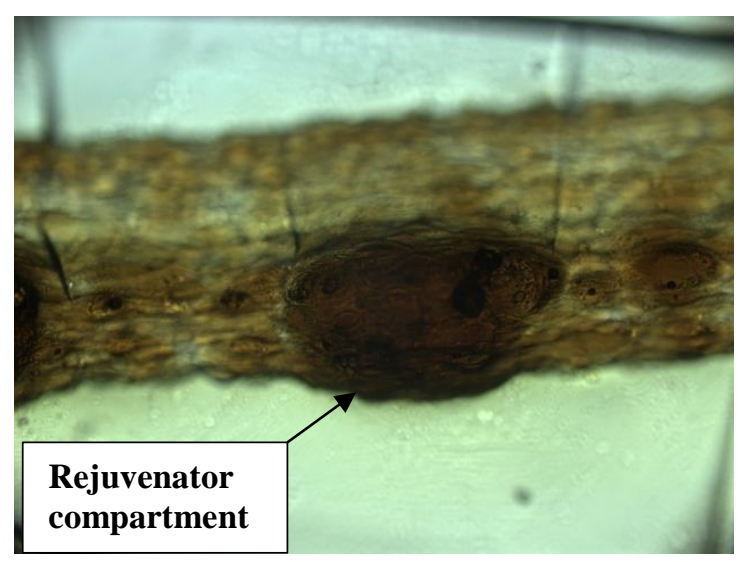

a)

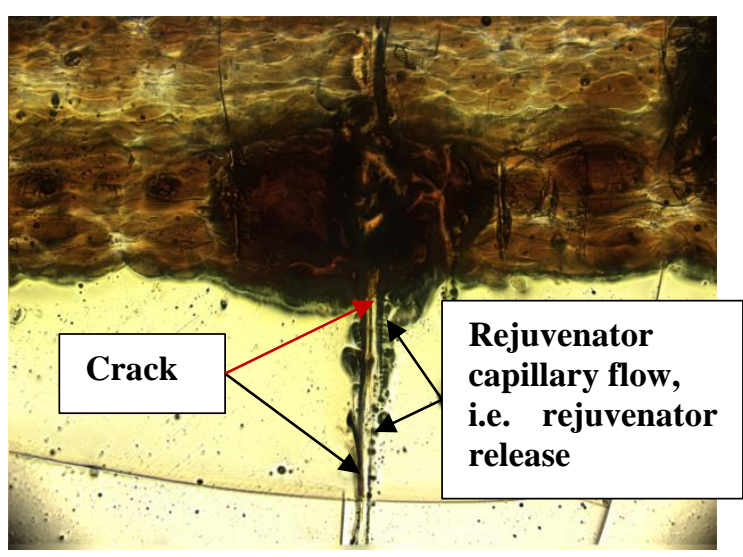

b)

1 Figure 7 Optical photomicrographs of alginate compartmented fibre containing rejuvenator release, a) 2 undamaged fibre, $b$ ) damaged fibre releasing the rejuvenator. Plane polarised light mode. Field of view is $3 \quad 1.5 \mathrm{~mm}$.

5 The results from the Uniaxial Tensile Strength (UTS) test are presented in Figure 8. The results show that the UTS of the fibres is $39 \mathrm{MPa}$ and Young's modulus (E) of 0.64GPa. These results confirm previous research findings which indicated that UTS of compartmented alginate fibres containing healing agent is in the range of $37-50 \mathrm{MPa}$ [25]. The results also show large variation in the test results, this is due to the variation in the compartment size. Prajer et. al. [25] indicated that fibres with large compartments have UTS of $37 \mathrm{MPa}$ and fibres with small compartments have UTS of 50MPa. Due to the large difference between asphalt mixing and compaction procedures (laboratory and plant) it is difficult to predict exact loading conditions that will be applied onto the fibres during the asphalt mixing process. It has been reported in literature that the typical compaction pressure applied during the asphalt pavement production process range from between 0.6MPa (Gyratory Compactor) and 12MPa (Duriez test) [34, 35]. These results indicate that compartmented fibres containing rejuvenator have sufficient mechanical strength to survive the asphalt pavement production process. Furthermore, these results also confirm that fibres have sufficient strength to reinforce the strength of the asphalt mastic matrix. The authors previously reported [30] that the UTS of asphalt mastic at a loading rate of $0.01 \mathrm{~mm} / \mathrm{s}$, is $0.5 \mathrm{MPa}$. this is substantially lower than the UTS of the alginate fibres (the lowest recorded fibre UTS was 13.12MPa). 


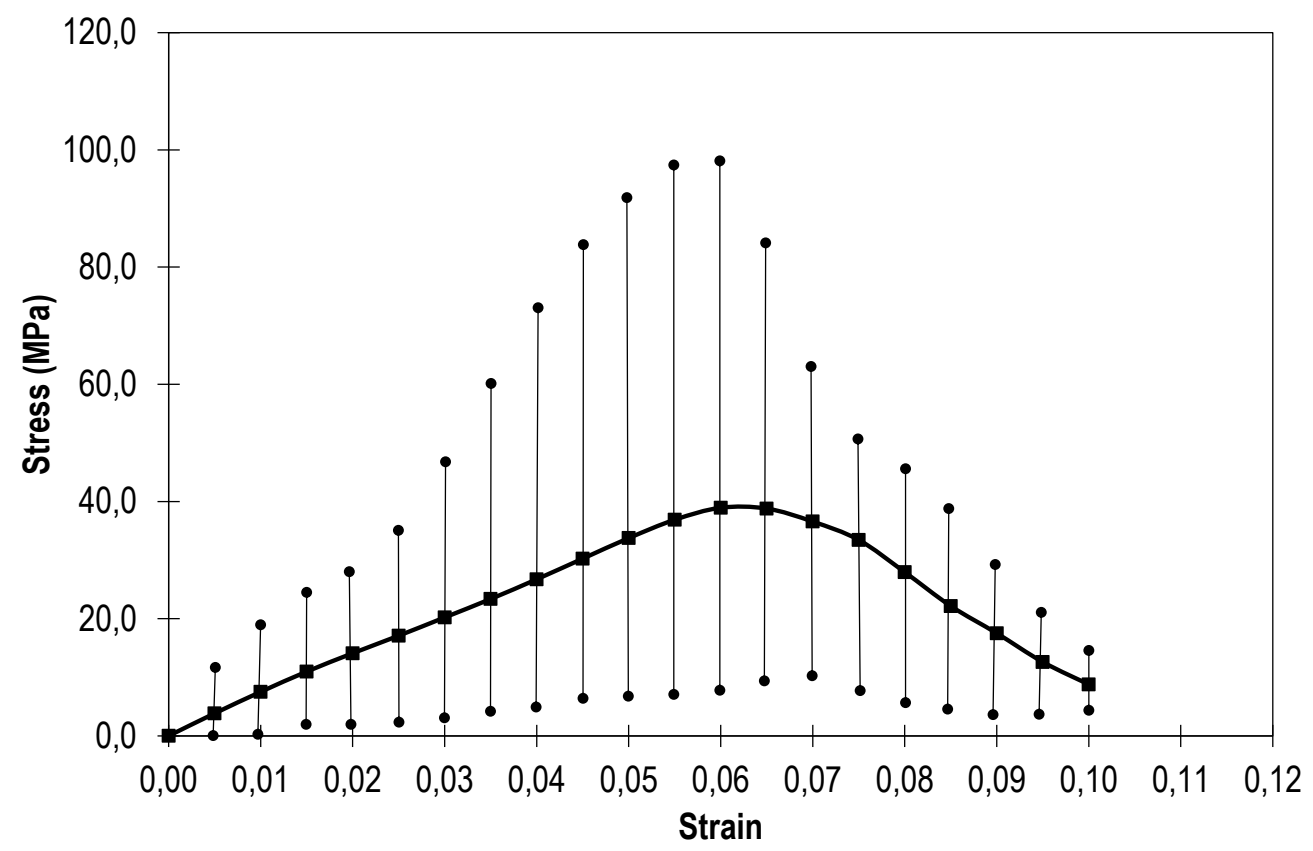

Figure 8 Uniaxial tensile test results of sodium alginate compartmented fibres containing rejuvenator 3

\section{$4 \quad 3.3$ Asphalt mixture}

5 Figure 9 shows the results of the TGA analysis. The compartmented fibres lost $25 \%$ of their 6 weight at $270^{\circ} \mathrm{C}$, and a further weight loss of $9 \%$ during the asphalt mixing process 7 (temperatures of $160^{\circ} \mathrm{C}$ ) most likely due to residual water evaporation from the calcium 8 alginate. These results indicate that the alginate fibre can, in principle, resist the high processing 9 temperatures of the asphalt mixing process.

10

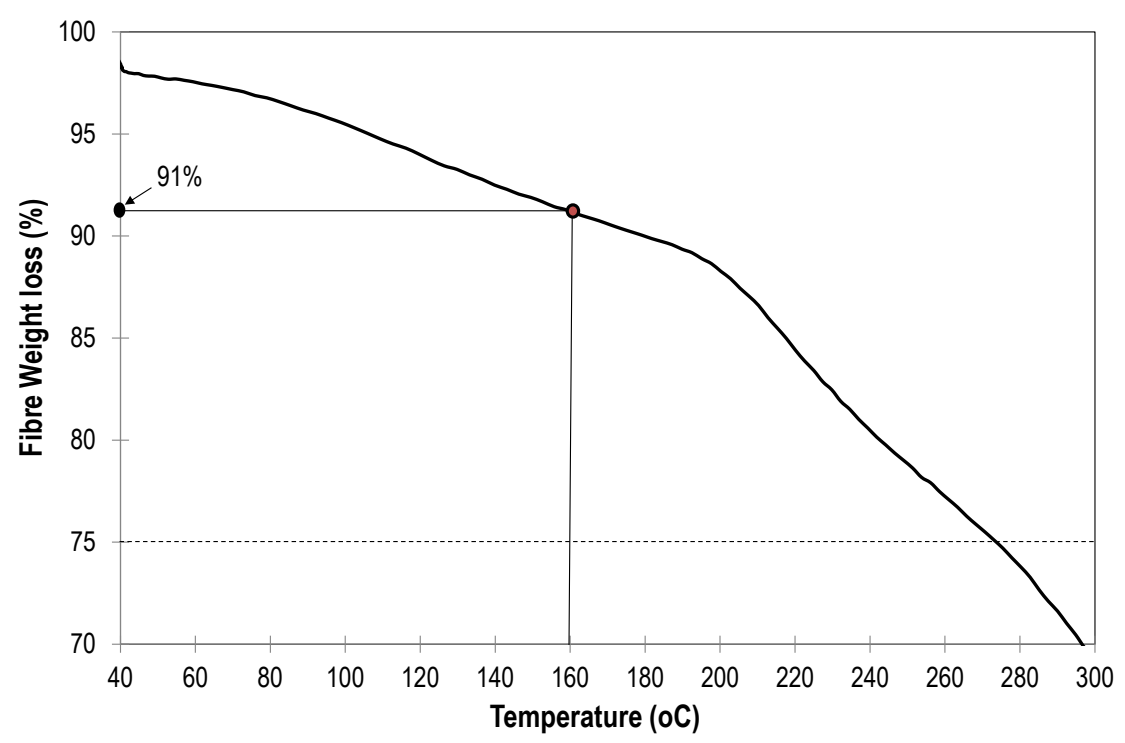

Figure 9 Sodium Alginate Compartmented fibres containing rejuvenator TGA test results. 
1 Micro x-ray tomography was used to investigate the survival of the alginate fibres during the 2 asphalt mixing and compaction process. Figure 10 shows a 3D reconstructed image of the fibres 3 within the asphalt specimen. Fibres account for $20 \%$ of the mix volume. To confirm that the 4 fibres were not cut during the asphalt mortar mixing process, the fibre length was measured using CT Scan images. The original length of fibres (when inserted into the mix) was $10 \mathrm{~mm}$ on average. The fibres measured in the CT Scan indicates an average fibre length of $8 \mathrm{~mm}$. However, because the edges of the fibres were embedded into the body of the specimen, the full length of the fibres could not be measured from the images. This indicates that that the fibres were not broken or damaged during the asphalt mixing process. Figure 10 shows intact fibres throughout the specimen, indicating a high fibre survival rate. These results correspond with the TGA and UTT results.

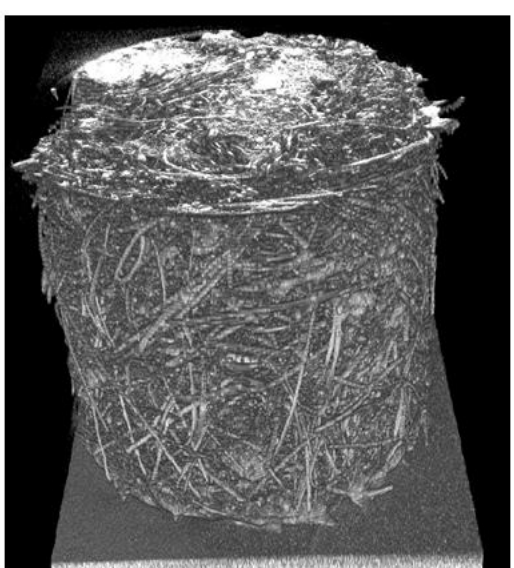

a)

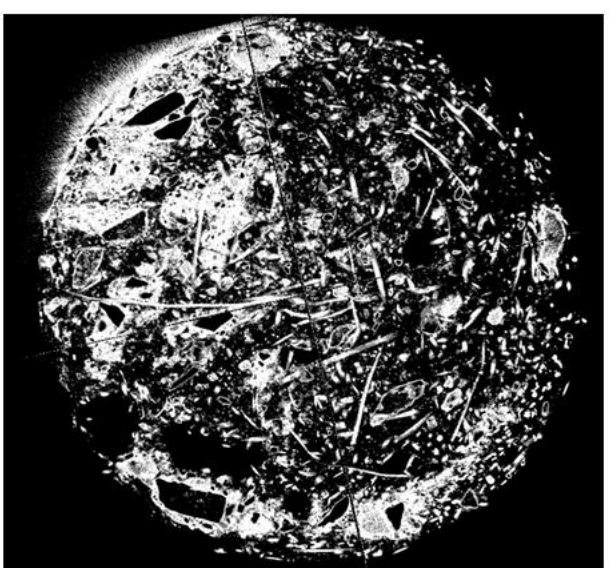

b)

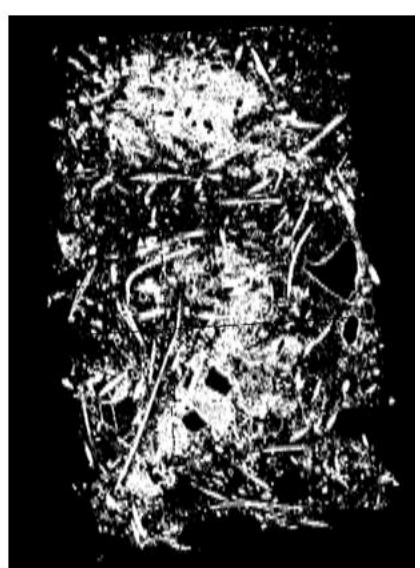

c)

Figure $10 \mathrm{X}$-ray tomographic images of fibres distribution in a porous asphalt mastic mix, a) 3D view of the test specimen, b) cross sectional view along the specimens diameter and c) cross sectional view along the specimens length.

The effect of ageing on the fibres within the asphalt mastic mix programme is presented in Figure 11. The results indicate that short term ageing ( 2 years) has no effect on the fibres, i.e. the stiffness of the asphalt mastic increases rather than decreases. However, longer term ageing (15 years) shows a softening of the asphalt mastic. This indicates that the rejuvenator is released. These results concur with those presented by Casado Barrasa et. al. [32], which indicates that short term ageing had no effect on the polymeric microcapsules containing rejuvenator, but that long term ageing resulted in the rejuvenator release and asphalt binder softening. Figure 12 illustrates that some of the fibres have survived the long term ageing process and did not disintegrate during the 3 PB test loading. These findings indicate that alginate is as durable as polymeric microcapsules (methanol-melamine-formaldehyde (MMF) 
1 prepolymer) [11, 32] and is a suitable material for the encapsulation of asphalt binder 2 rejuvenator.

3

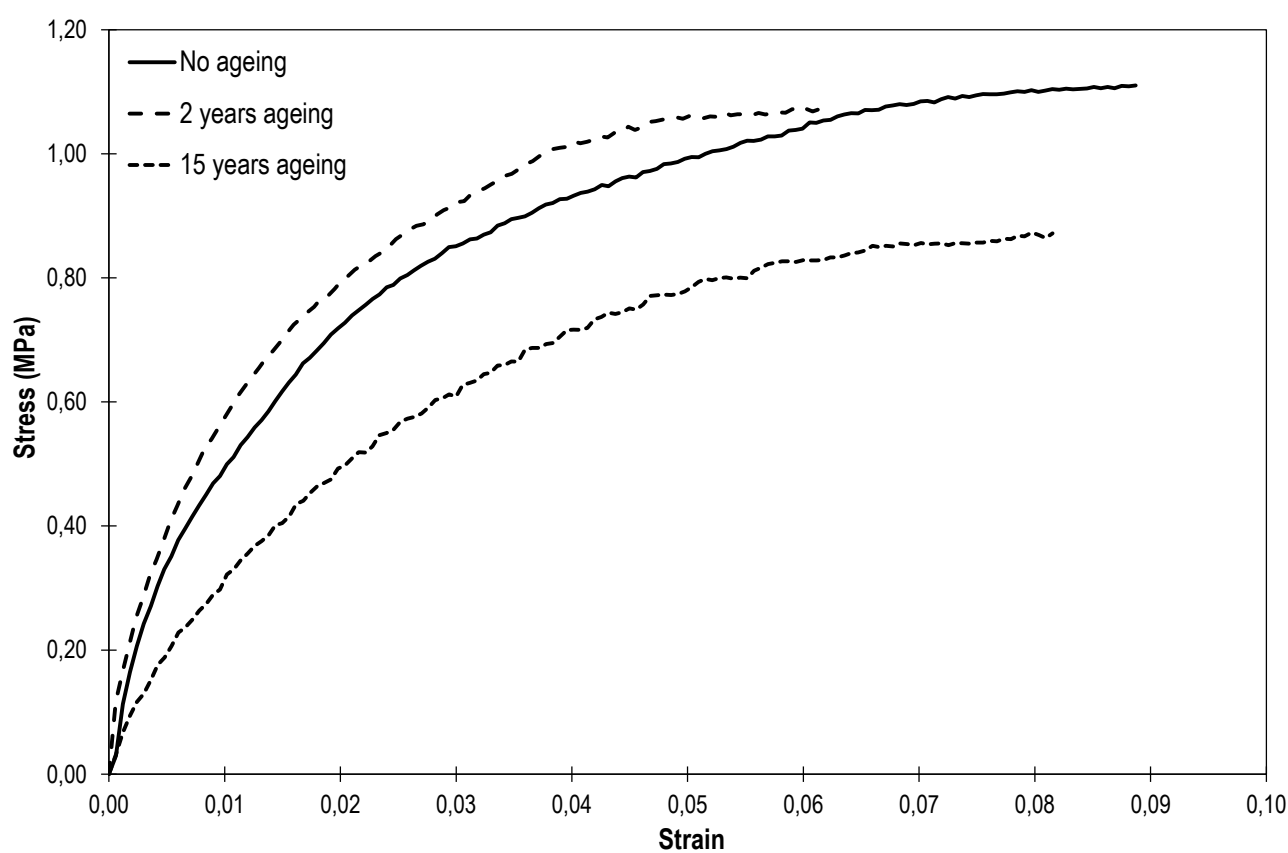

Figure 11 Short and long term ageing effect on the strength of the asphalt mastic mix containing fibres

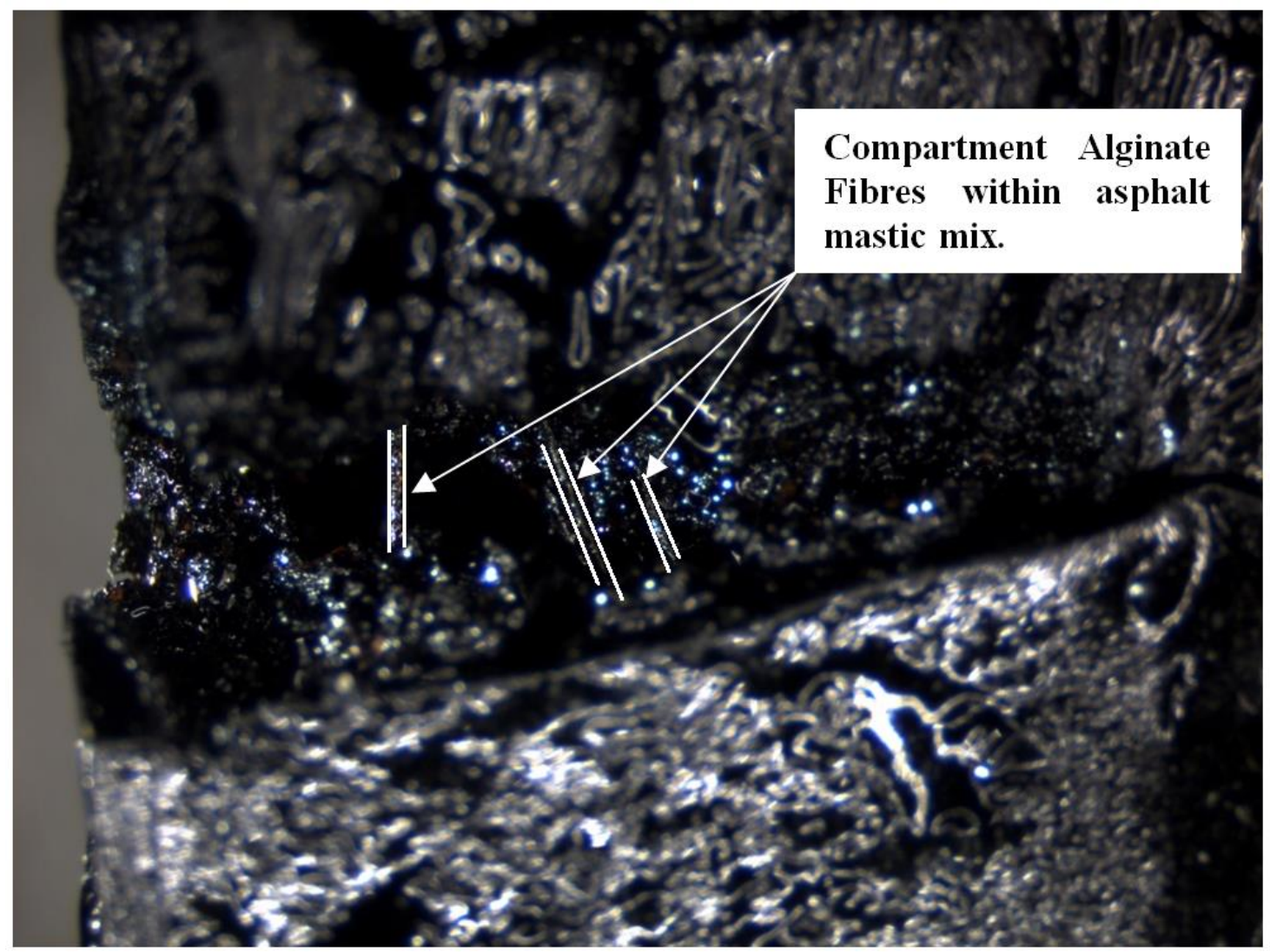

8 Figure 12 Long term aged asphalt mastic test sample containing fibres, crack after 3PB test. 


\section{$1 \quad 3.4$ Healing efficiency}

2 The strain at break of the fibres obtained from the fibre UTS was used to estimate the strain at 3 which fibre compartments will break. With this, $0.06 \%$ strain was selected for the first bending 4 leading to the opening of all the compartments in the cross-section, healing agent release and micro cracks development in the outer layer of the beam. An analysis of the three-point bending results and a visual observation by optical microscopy confirmed the fibre breakage and the release of rejuvenator into the asphalt mastic mix, see Figure 13.

Figure 13 A broken fibre releasing the rejuvenator at asphalt mastic mix crack surface.

Figure 14 and 15 show the results of the 3PB test and material strength and its recovery after healing. Both tests, conducted at ambient temperature $\left(20^{\circ} \mathrm{C}\right)$ and at low temperature $\left(-5^{\circ} \mathrm{C}\right)$, demonstrated that asphalt mastic mixtures containing fibres outperformed standard mixtures, i.e. mixtures that did not contain fibres. Asphalt mastic mixtures containing fibres were $36 \%$ stronger than those without. The results from the tests conducted at $20^{\circ} \mathrm{C}$ (Figure $14 \mathrm{a}$ ), show good recovery of material strength for both materials, with and without fibres. Overall, the results indicate very good strength recovery by the material without fibres (Figure $14 \mathrm{~b}$ ), which reduces the requirement for the fibres, i.e. healing system, in the mix. However, the asphalt mastic mixtures containing fibres encapsulating rejuvenator showed better stiffness recovery in comparison to the mixtures without fibres. This finding indicates that bitumen in the mix was rejuvenated and that the mix will be less prone to rutting damage. These results show the potential for using rejuvenator encapsulated in alginate compartmented fibres to improve the strength of self-healing asphalt pavements following minor damage. 
1 A second test, performed at a low temperature $\left(-5^{\circ} \mathrm{C}\right)$, was conducted to investigate strength 2 recovery and healing efficiency after large crack propagation. The results, shown in Figure 15, 3 confirm that the samples containing fibres and encapsulated rejuvenator have a better healing 4 efficiency. However, healing efficiency was very low in both asphalt mixtures.

- $1^{\text {st }}$ healing stage (3h after testing) specimens with fibres recovered $10 \%$ of its strength,

- $\quad 2^{\text {nd }}$ healing stage $(12 \mathrm{~h}$ after test) strength recovery fell to $5 \%$.

Whereas for specimens without fibres:

- $\quad 1^{\text {st }}$ healing stage ( $3 \mathrm{~h}$ after testing) specimens recovered only $5 \%$ of their strength,

- $\quad 2^{\text {nd }}$ healing stage ( $12 \mathrm{~h}$ after test) specimens showed no strength recovery.

These test results indicate that the self-healing mechanisms perform better when healing micro cracks than macro cracks. To increase healing efficiency at large crack or where there has been extensive damage, a higher amount of rejuvenator must be supplied to the damage site or the healing temperature must be increased.

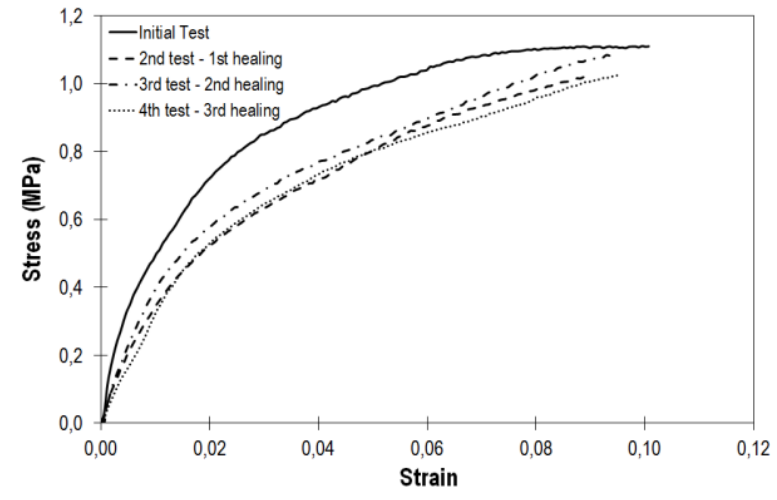

a)

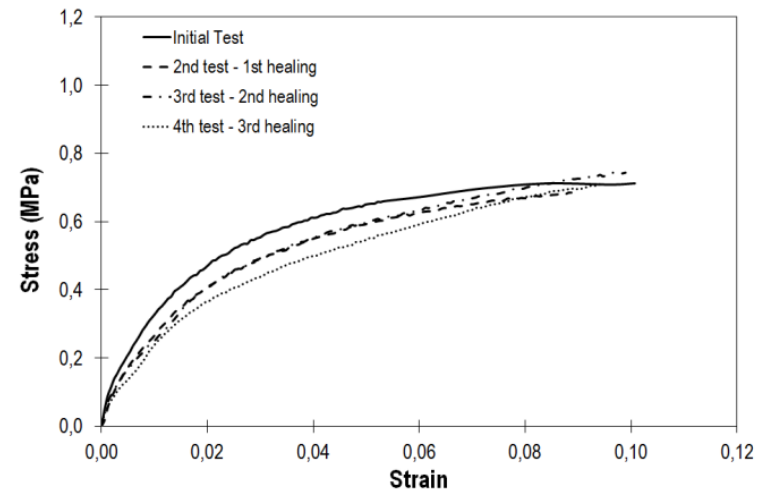

b)

17 Figure 14 Typical 3PBT load vs deflection plots for asphalt mastic mix at $20^{\circ} \mathrm{C}$, at varying healing stages: 18 a) mix containing fibres, b) mix without fibres. 


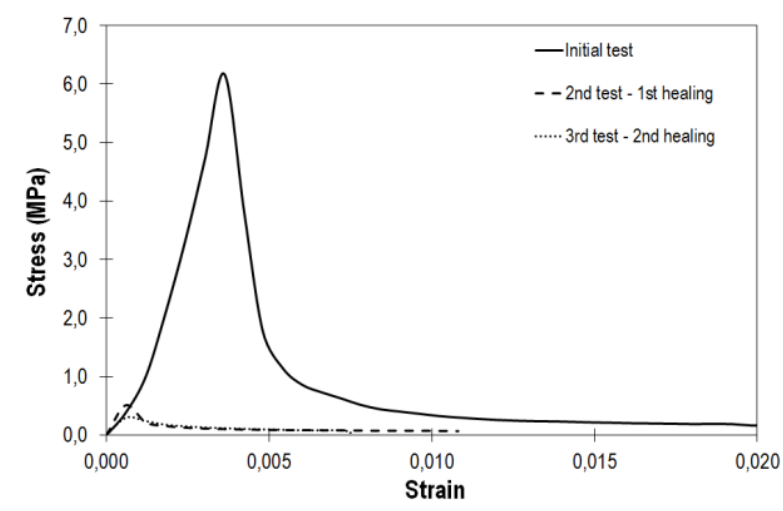

a)

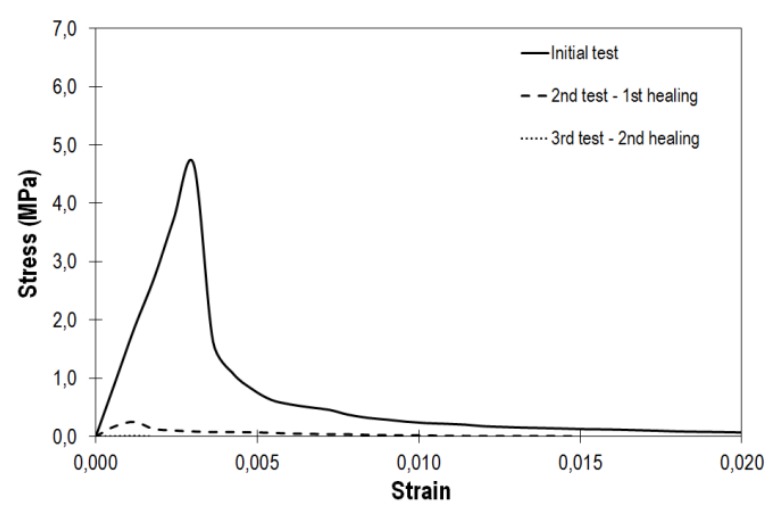

b)

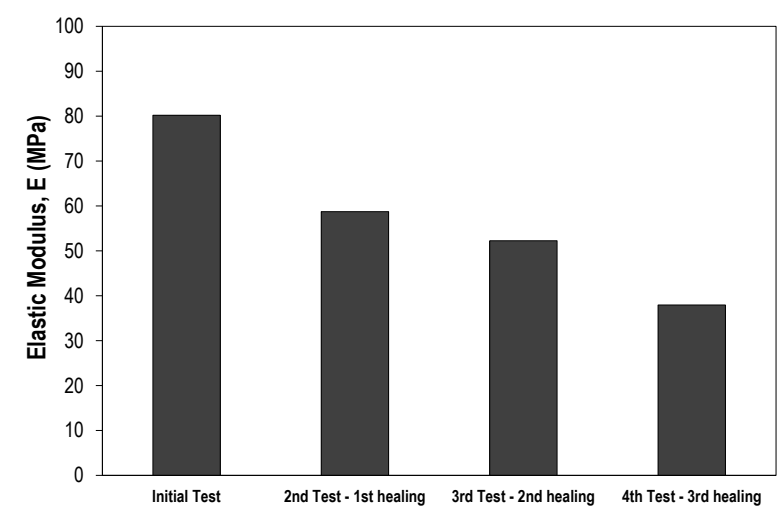

a)

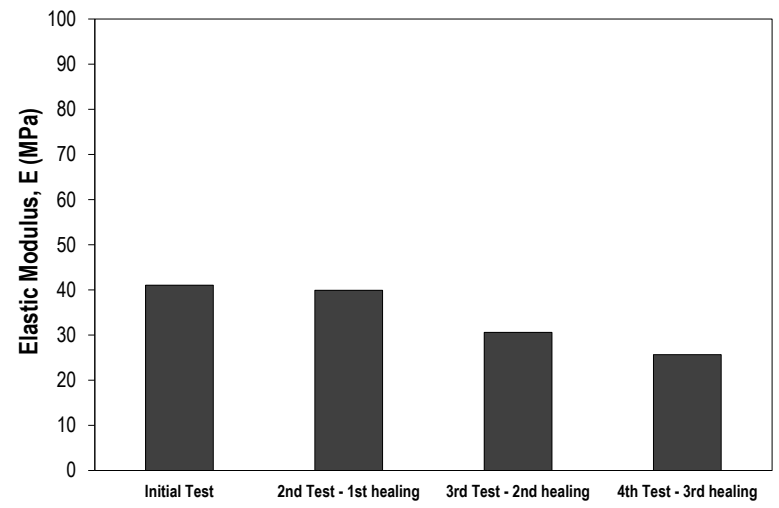

b)

Figure 16 Elastic modulus for asphalt mastic mix at $20^{\circ} \mathrm{C}$, at varying healing stages: a) mix containing fibres, 18 b) mix without fibres. 


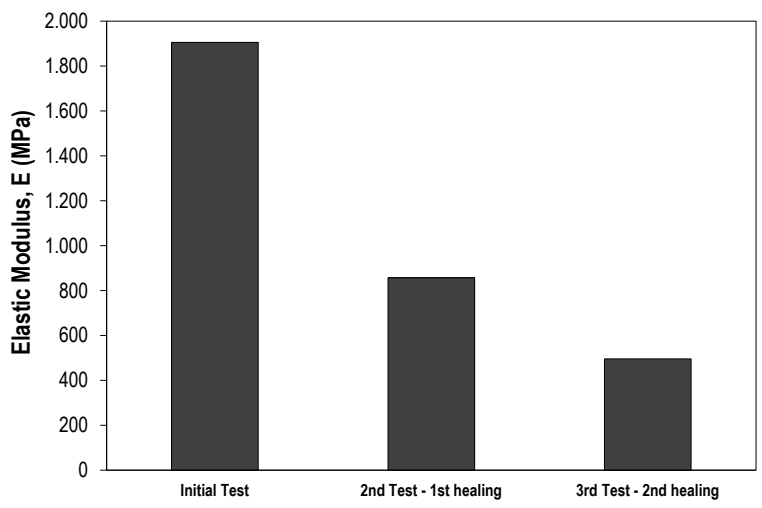

a)

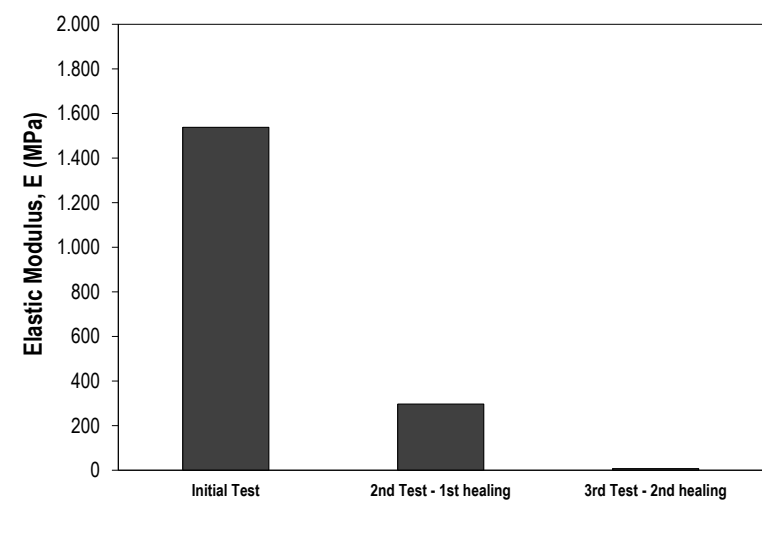

b)

Figure 17 Elastic modulus for asphalt mastic mix at $-5^{\circ} \mathrm{C}$, at varying healing stages: a) mix containing fibres, b) mix without fibres.

\section{Conclusions}

This work has demonstrated how alginate comparted fibres can be used for the encapsulation of rejuvenator and how they perform within asphalt mastic mixtures. The results demonstrated that alginate fibres survived the asphalt mix production process and can increase the strength of the asphalt mastic mixture by $36 \%$. The mechanical properties of the fibres allow local failure and compartment opening before asphalt mastic mixture failure herby locally releasing the healing agent (i.e. rejuvenator). The research illustrated that alginate fibres were capable of healing local micro cracks when the asphalt mastic mixtures sustained low level of damage. However, once major damage occurred to the asphalt mastic mixture, the alginate fibres could only promote residual healing. This preliminary study indicates that alginate fibres encapsulating bitumen rejuvenator have the potential to heal asphalt mastic mixtures. As a result, they hold potential for the future development of self-healing asphalt technology.

\section{Acknowledgements}

The authors wish to thank: Dr. Bert Jan Lommerts and Dr. Irina Catiugă, Latexfalt BV, for their support to the project. Authors would also like to thank Mr. Arjan Thijssen for his assistance with the environmental scanning electron microscope and micro CT scan tests. This research was conducted under the Marie Curie IEF research funding, research project Self-healing Asphalt for Road Pavements (SHARP), project number 622863.

\section{References}

1. Fisher, H., Self repairing materials - dream or reality. Natural Science, 2010. 2 (8): p. $873-901$. 
2. Silva, H.M.R.D., J.R.M. Oliveira, and C.M.G. Jesus, Are totally recycled hot mix asphalts a sustainable alternative for road paving? Resources, Conservation and Recycling, 2012. 60: p. 38-48.

3. Brownridge, J. The role of an asphalt rejuvenator in pavement preservation: use and need for asphalt rejuvenation. in 1st International Conf. on Pavement Preservation. 2010. Newport Beach, USA.

4. Tabaković, A., et al., The Influence of Recycled Asphalt Pavement on the Fatigue Performance of Asphalt Concrete Base Courses. ASCE Journal of Materials in Civil Engineering, 2010. 22(6): p. 643 - 650.

5. Tabaković, A., Recycled Asphalt (RA) for Pavements, in Handbook of Recycled Concrete and Demolition Waste, F. Pacheco-Torgal, et al., Editors. 2013, Woodhead Publishing. p. $394-419$.

6. Garcia, A., J. Jelfs, and C.J. Austin, Internal asphalt mixture rejuvenation using capsules. Construction and Building Materials, 2015. 101: p. 8.

7. Su, J.F., et al., Investigation the possibility of a new approach of using microcapsules containing waste cooking oil; in-situ rejuvenation. Construction and Building Materials, 2015. 74: p. 83-92.

8. Steyn, W., Potential application of nanotechnology in pavement engineering. ASCE Journal of Transport Engineering, 2009. 135(10): p. 764 - 772.

9. Shen, J., S. Amirkhanian, and J.A. Miller, Effects of rejuvenating agents on superpave mixtures containing reclaimed asphalt pavement. ASCE Journal of Materials in Civil Engineering, 2007. 19(5): p. 376-84.

10. Su, J.F., et al., Experimental investigation of self healing behaviour of bitumen/microcapsule composites by modified beam on elastic foundation method. Materials and Structures, Springer publication, RILEM, 2014.

11. Su, J.F. and E. Schlangen, Synthesis and physicochemical properties of high compact microcapsules containing rejuvenator applied in asphalt. Chemical Engineering Journal, 2012. 198-199: p. 289-300.

12. García, Á., E. Schlangen, and M. van de Ven, Two ways of closing cracks on asphalt concrete pavements: Microcapsules and Induction Heating. Key Enginering Materials, 2010. 417-418: p. 573-576.

13. Sun, D., J. Hu, and X. Zhu, Size optimization and self-healing evaluation of microcapsules in asphalt binder. Colloid Polymer Science, 2015. 293: p. 12.

14. Gibney, A., Analysis of Permanent Deformation of Hot Rolled Asphalt in Civil Engineering. 2002, University College Dublin.

15. Anderson, F.A., Final Report on the Safety Assessment of Melamine/Formaldehyde Resin. Journal of the American College of Toxicology, 1995. 14(5): p. 373-385.

16. Zlopasa, J., E.A.B. Koenders, and S.J. Picken. Using bio-based polymers for curing cement-based materials. in 1st International Conference on Ageing of Materials \& Structures, AMS 14. 2014. Delft, The Netherlands.

17. Draget, K.I., G. Skjåk-Bræk, and O. Smidsrød, Alginate based new materials. International Journal of Biological Macromolecules, 1997. 21(1-2): p. 8.

18. Grasdalen, H., B. Larsen, and O. Smisrod, 13C-n.m.r. studies of monomeric composition and sequence in alginate. Carbohydrate Research, 1981. 89(2): p. 12.

19. Linker, A. and R.S. Jones, A New Polysaccharide Resembling Alginic Acid Isolated from Pseudomonads. The Journal of Biological Chemistry, 1966. 241(16): p. 6.

20. Laurienzo, P., Marine Polysaccharides in Pharmaceutical Applications: An Overview. Marine Drugs, 2010. 8(9): p. 30.

21. Balakrishnana, B., et al., Evaluation of an in situ forming hydrogel wound dressing based on oxidized alginate and gelatin. Biomaterials, 2005. 26(32): p. 8. 
22. Matthew, I.R., et al., Subperiosteal behaviour of alginate and cellulose wound dressing materials. Biomaterials, 1995. 16(4): p. 4.

23. Palin, D., V. Wiktor, and H.M. Jonkers, Bacteria-based agent for self-healing marine concrete, in 5th International Conference on Self-Healing Materials. 2015: Durham, North Carolina, USA.

24. van der Zwaag, S., et al., Review of current strategies to induce self-healing behaviour in fibre reinforced polymer based composites. Materials Science and Technology, 2014. 30(13a): p. 9.

25. Prajer, M., et al., Direct and indirect observation of multiple local healing events in successively loaded fibre reinforced polymer model composites using healing agentfilled compartmented fibres. Composites Science and Technology, 2015. 106: p. 7.

26. Mookhoek, S.D., H.R. Fischer, and S. van der Zwaag, Alginate fibres containing discrete liquid filled vacuoles for controlled delivery of healing agents in fibre reinforced composites. Composites Part A: Applied Science and Manufacturing, 2012. 43(12): p. 7.

27. Kringos, N., et al., On the development of a new test methodology for moisture damage susceptibility of asphalt concrete, in 5th International Conference 'Bituminous Mixtures and Pavements'. 2011: Thessaloniki, Greece. p. 857 - 867.

28. Bitumen, S., The Shell Bitumen Handbook. 1991: Shell Bitumen U.K.

29. American Society for Testing Materials, A., E 1820-01: Standard test method for measurement of fracture toughness. 2006, Annual Book of ASTM Standards: Philadelphia, PA, USA.

30. Tabakovic, A., et al., Modelling the quasi-static behaviour of bituminous material using a cohesive zone model. Engineering Fracture Mechanics,, 2010. 77(13): p. 15.

31. Kliewer, J.E., C.A. Bell, and D.A. Sasnovske, Investigation of the relationship between field performance and laboratory ageing properties of asphalt mixtures, in Engineering Properties of Asphalt Mixtures and the Relationship to their Performance, G.A. Huber and D.S. Decker, Editors. 1995.

32. Casado Barrasaa, R., et al., Addressing durability of asphalt concrete by self-healing mechanism. Procedia - Social and Behavioral Sciences, 2014. 162: p. 188.

33. Qiu, J., et al. Characterization and modelling of self healing of bituminous materials towards durable asphalt pavement. in International Symposium on Heavy Duty Asphalt Pavements and Bridge Deck Pavements. 2012. Nanjing, China, : ISAP.

34. Hartman, A.M., M.D. Gilchrist, and G. Walsh, Effect of mixture compaction on indirect tensile stiffness and fatigue. Journal of Transport Engineering, 2001. 127(5): p. 9.

35. Bonnot, J. Selection and use of the procedures for laboratory compaction of bitumen mixtures. in Performance related test procedures for bitumen mixtures. 1997. Dublin: Boole Press Ltd. 